\title{
GMR
}

\section{Expression of an alfalfa (Medicago sativa L.) peroxidase gene in transgenic Arabidopsis thaliana enhances resistance to $\mathrm{NaCl}$ and $\mathrm{H}_{2} \mathrm{O}_{2}$}

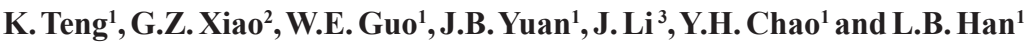 \\ ${ }^{1}$ Turfgrass Research Institute, College of Forestry, Beijing Forestry University, \\ Beijing, China \\ ${ }^{2}$ The College of Horticulture and Garden, Yangtze University, Jingzhou, China \\ ${ }^{3}$ Institute of Grassland Research, Chinese Academy of Agricultural Sciences, \\ Hohhot, China
}

Corresponding authors: Y.H. Chao / L.B. Han

E-mail: chaoyuehui@163.com / hanliebao@163.com

Genet. Mol. Res. 15 (2): gmr. 15028002

Received November 5, 2015

Accepted February 12, 2016

Published May 23, 2016

DOI http://dx.doi.org/10.4238/gmr.15028002

\begin{abstract}
Peroxidases (PODs) are enzymes that play important roles in catalyzing the reduction of $\mathrm{H}_{2} \mathrm{O}_{2}$ and the oxidation of various substrates. They function in many different and important biological processes, such as defense mechanisms, immune responses, and pathogeny. The POD genes have been cloned and identified in many plants, but their function in alfalfa (Medicago sativa L.) is not known, to date. Based on the POD gene sequence (GenBank accession No. L36157.1), we cloned the POD gene in alfalfa, which was named MsPOD. MsPOD expression increased with increasing $\mathrm{H}_{2} \mathrm{O}_{2}$. The gene was expressed in all of the tissues, including the roots, stems, leaves, and flowers, particularly in stems and leaves under light/dark conditions. A subcellular analysis showed that $M S P O D$ was localized outside the cells. Transgenic Arabidopsis with MsPOD exhibited increased resistance to $\mathrm{H}_{2} \mathrm{O}_{2}$ and $\mathrm{NaCl}$. Moreover, POD activity in the transgenic plants was significantly higher than that in wild-type
\end{abstract}


Arabidopsis. These results show that $M S P O D$ plays an important role in resistance to $\mathrm{H}_{2} \mathrm{O}_{2}$ and $\mathrm{NaCl}$.

Key words: Medicago sativa L.; Transgenic Arabidopsis thaliana; Peroxidase; Abiotic stress

\section{INTRODUCTION}

Under natural conditions, plants are subject to abiotic and biotic stress. Plants produce reactive oxygen under normal growth conditions, and can be induced to produce a large quantity of reactive oxygen species (ROS) under different stressors that can damage plants. To decrease the damage caused by ROS, plants activate the enzymatic system, which mainly consists of superoxide dismutase (SOD), catalase (CAT), ascorbate peroxidases (APX), and peroxidase (POD). PODs (EC 1.11.1.7), a family of isozymes found in all plants, can catalyze the reduction of $\mathrm{H}_{2} \mathrm{O}_{2}$ via the transport of electrons to various donor molecules, including phenolic compounds, lignin precursors, and auxin (Hiraga et al., 2001; Passardi et al., 2005).

PODs play an important role in abiotic stress tolerance in various plant species, including rice (Oryza sativa) (Demiral and Turkan 2005), barley (Hordeum uhulgare) (Liang et al., 2003), tomato (Solanum lycopersicum) (Mittova et al., 2004), pepper (Capsicum baccatum) (Gonçalves et al., 2013), and Kentucky bluegrass (Poa pratensis) (Li et al., 2014). Some plant POD genes have been expressed using transgenic techniques. The phenotypes of these transgenic plants yield information about gene function, such as TPX2 improves the germination rate of tomato (Lycopersicon esculentum) under $\mathrm{NaCl}$ stress (Amaya et al., 1999) and swpal and swpa4 increase the $\mathrm{H}_{2} \mathrm{O}_{2}$-scavenging capacity of sweet potato (Ipomoea batatas) (Yun et al., 2000; Kim et al., 2008).

Due to the physiologically important roles of PODs in plants, they have become the subject of a broad range of biochemical and molecular biological studies. A considerable amount of research on POD genes has been conducted in Arabidopsis, rice, and tomato, and it is known that POD genes play different roles in plant growth and developmental regulation. Alfalfa (Medicago sativa L.) is one of the most important forage grasses in the world, and is worthy of genetic study in order to improve its quality. The function of POD in alfalfa is not well known, and few studies have been conducted on it. In particular, the role of alfalfa POD in stress responses and tolerances is unknown. A detailed analysis of alfalfa POD will provide useful information about the alfalfa genes that are involved in stress responses and tolerances. Therefore, the isolation and characterization of POD in alfalfa will provide new insights into the biochemistry, roles, and regulation of these genes in transgenic plants.

In this study, we cloned a POD gene from the alfalfa cultivar 'Zhongmu No.1' that was named $M s P O D$. In order to detect to which abiotic stressor $M s P O D$ responds, we analyzed its expression in response to $\mathrm{H}_{2} \mathrm{O}_{2}$, salt, abscisic acid (ABA), gibberellic acid (GA), salicylic acid (SA), and methyl jasmonate (MeJA). In addition, we measured the physiological traits of transgenic MsPOD Arabidopsis plants after treatment with salt and $\mathrm{H}_{2} \mathrm{O}_{2}$. The results show that the salt and oxidative tolerance of transgenic Arabidopsis plants significantly increased compared with that of non-transgenic Arabidopsis plants, and indicate that MSPOD plays an important role in increasing plant tolerance to abiotic stressors. 


\section{MATERIAL AND METHODS}

\section{Plant material and growth conditions}

The alfalfa seeds used in this study were obtained from the Chinese Academy of Agricultural Sciences. All of the Arabidopsis thaliana lines had a Col-0 background. Plants were grown in a controlled room at $22^{\circ} \mathrm{C}$ under long-day (LD) conditions $(16 \mathrm{~h}$ light and $8 \mathrm{~h}$ dark). For growth on tissue culture plates, Arabidopsis seeds were sown on $1 / 2$ Murashige and Skoog (MS) solid medium containing $1 \%$ sucrose and $0.8 \%$ agar, and incubated at $22^{\circ} \mathrm{C}$ under LD conditions.

\section{Amplification of full length $M s P O D$}

Total RNA was isolated from 10-day-old seedlings by the TRIzol method and then extensively pretreated with RNase-free DNase to eliminate any contaminating genomic DNA before use. First-strand synthesis was performed using PrimeScript ${ }^{\mathrm{TM}}$ Reverse Transcriptase (TAKARA, Japan). Based on the sequence of the POD gene in GenBank, a pair of genespecific primers, MsPOD-f and MsPOD-r (Table 1), was designed to amplify the full-length cDNA of $M S P O D$. The PCR conditions were as follows: $30 \mathrm{~s}$ at $95^{\circ} \mathrm{C}, 30 \mathrm{~s}$ at $55^{\circ} \mathrm{C}$, and $2 \mathrm{~min}$ at $72{ }^{\circ} \mathrm{C}$ for 30 cycles. The PCR products were separated by electrophoresis on a $1 \%$ agarose gel stained with ethidium bromide and purified using a DNA gel extraction kit (Biomed, Beijing, China). The products were cloned into a pEASY ${ }^{\circledR}-\mathrm{T} 1$ vector (TransGen, Beijing, China) and then transformed into Escherichia coli DH5a. Recombinant plasmids were sequenced by the Beijing Genomics Institution (Beijing, China).

Table 1. Primers used in the study.

\begin{tabular}{|c|c|c|}
\hline Primer & Sequence (5'-3') & Purpose of primer \\
\hline MsPOD-f & AATAATGAACTCTTCTTTCAATCTC & \multirow[t]{2}{*}{ RT-PCR of $M S P O D$} \\
\hline MsPOD-r & CTCTAGAACACACTCTTTATTTTCTTA & \\
\hline MPF & gggCTCGAGATGAACTCTTCTTTCAATC & \multirow[t]{2}{*}{ Construct subcellular localization vector of $M S P O D$} \\
\hline MPR & cccACTAGTAGGTATGAGCTAACAATACC & \\
\hline POD-1 & CTCTTTTCTTTGAAGCTTTTAAGGC & \multirow[t]{2}{*}{ qRT-PCR analysis of $M s P O D$} \\
\hline POD-2 & ATCCTCTGACGACTCTCTGATGACT & \\
\hline PODf & cccTCTAGAATGAACTCTTCTTTCAATC & \multirow[t]{2}{*}{ Construct plant expression vector to transform Arabidopsis } \\
\hline PODr & cccCCCGGGTATGAGCTAACAATACC & \\
\hline UBQ-f & GCAGCAACCAACGAAGCAAGA & \multirow[t]{2}{*}{ qRT-PCR of alfalfa Ubiquitin gene used as internal control } \\
\hline UBQ-r & CACCACGAAGACGTAGGACAAGG & \\
\hline
\end{tabular}

\section{Bioinformatics analysis}

The amino acid sequence for MsPOD was obtained by cDNA translation using DNAMAN 6.0 software, and related proteins were obtained by a BLAST analysis of the National Center for Biotechnology Information database. Phylogenetic analysis was conducted using MEGA 5.0 software by the neighbor-joining method, and a bootstrap analysis was obtained from 1000 replications (Tamura et al., 2011). The theoretical isoelectric point (pI) and molecular weight $(\mathrm{Mw})$ were predicted using the Compute $\mathrm{pI} / \mathrm{Mw}$ tool (http://web.expasy. org/compute_pi/), and potential signal peptide cleavage sites were identified using SignalP 4.1 Server (http://www.cbs.dtu.dk/services/SignalP/) (Petersen et al., 2011). To predict the subcellular localization of MsPOD, the protein sequence was analyzed using the PSORT program (http://www.psort.org/). 


\section{Subcellular localization of MsPOD}

To ascertain the subcellular localization of MsPOD, two primers, MPF and MPR (Table 1), were designed to amplify the coding DNA sequence of MSPOD. The PCR product was digested with $X b a \mathrm{I}$ and $S m a \mathrm{I}$ and subcloned into the vector pA7-GFP, which was digested with the same enzymes. The MsPOD-GFP fusion construct was transformed into onion epidermal cells by particle bombardment, as described in the manual of the highpressure gas gene gun (GJ-1000; Ningbo Scientz Biotechnology, China) used. After $16 \mathrm{~h}$ of dark treatment, the onion epidermal cells were visualized with a confocal laser-scanning microscope (TE2000-E; Nikon, Japan).

\section{Quantitative real-time PCR}

In order to investigate the expression patterns of $M S P O D$ in alfalfa, quantitative RT-PCR reactions were conducted for the roots, stems, leaves, and flowers. $M S P O D$ expression profiles were determined in 10-day-old alfalfa seedlings induced by $2 \mathrm{mM} \mathrm{H}_{2} \mathrm{O}_{2}, 20 \mu \mathrm{M} \mathrm{GA}_{3}, 20 \mu \mathrm{M}$ $\mathrm{ABA}, 3 \mathrm{mM}$ MeJA, and $200 \mathrm{mM} \mathrm{NaCl}$, over a period of $24 \mathrm{~h}$. The gene-specific primers used were POD-1 and POD-2 (Table 1). The qRT-PCR was performed on 96-well blocks using an Applied Biosystems 7500 Real-Time PCR system with SYBR ${ }^{\circledR}$ Green I Master Mix in a volume of $25 \mu \mathrm{L}$. The two-step thermal cycling profile used was $15 \mathrm{~s}$ at $95^{\circ} \mathrm{C}$ and $1 \mathrm{~min}$ at $68^{\circ} \mathrm{C}$. The alfalfa Ubiquitin gene was used as a control in order to normalize the amount of cDNA. Relative expression was calculated using the comparative $\Delta \Delta$ threshold cycle method (Chao et al., 2009). All of the results are reported as means of at least three independent RNA extractions (including three technical replicates) with their corresponding standard deviations (SD).

\section{Plasmid construction and Arabidopsis transformation}

The PCR products were purified and cloned into a binary plasmid (pBI121) at the $X b a \mathrm{I}-$ SmaI sites, which generated the plant expression vector $35 \mathrm{~S}_{\text {pro }}: M s P O D$. The $35 \mathrm{~S}_{\text {pro }}:: M s P O D$ construct was transferred into wild-type (WT) Arabidopsis plants by the floral dip method (Clough and Bent 1998). Transgenic seeds were selected on $1 / 2$ MS plates with $50 \mathrm{mg} / \mathrm{L}$ kanamycin.

\section{$\beta$-glucuronidase (GUS) staining}

Histochemical GUS staining in the transgenic plants was performed as described previously (Cervera 2005). Briefly, the plant materials were stained in GUS assay solution containing $1 \mathrm{mM}$ 5-bromo-4-chloro-3-indole- $\beta$-D glucuronide, $1 \mathrm{mM}$ ethylenediaminetetraacetic acid, $5 \mathrm{mM}$ potassium ferrocyanide, $5 \mathrm{mM}$ potassium ferricyanide, and $0.1 \%$ Triton $\mathrm{X}-100$ in $500 \mathrm{mM}$ potassium phosphate buffer, $\mathrm{pH}$ 7.0. After washing the samples with ethanol, GUS images were taken with a Canon PowerShot G3 digital camera (Cannon Inc.).

\section{Analysis of POD and CAT activity}

Leaves from two-week-old transgenic and WT seedlings were harvested. POD and CAT activity was determined using the method of Maehly and Chance (Maehly and Chance 1954), with modifications. For the POD analysis, the reaction mix contained $50 \mu \mathrm{L}$ of enzyme 
extract, $1.42 \mathrm{~mL} 10 \mathrm{mM}$ phosphate buffer, $\mathrm{pH} 7.0$, and $25 \mu \mathrm{L} 20 \mathrm{mM}$ guaiacol. The reaction started with the addition of $10 \mu \mathrm{L} 40 \mathrm{mM} \mathrm{H}_{2} \mathrm{O}_{2}$. POD activity was assayed by recording the increase in absorbance at $470 \mathrm{~nm}$ for $1 \mathrm{~min}$. For the CAT assay, the reaction mixture contained $100 \mu \mathrm{L}$ of extracted solution, $45 \mathrm{mM} \mathrm{H}_{2} \mathrm{O}_{2}$, and $50 \mathrm{mM}$ sodium phosphate buffer, $\mathrm{pH}$ 7.0. The reaction started with the addition of the enzyme solution. The decrease in absorbance at 240 $\mathrm{nm}$ was read every $10 \mathrm{~s}$ for $1 \mathrm{~min}$.

\section{RESULTS}

\section{Isolation of $M S P O D$ and sequence analysis}

The full-length cDNA of $M s P O D$, including a 1062-bp coding domain sequence that encodes a polypeptide with 353 amino acids (Figure 1A), was cloned from alfalfa using the primers MsPOD-f and MsPOD-r. Amino acid sequence analysis revealed that the theoretical $\mathrm{pI} / \mathrm{Mw}$ was 5.76/38200.02. A potential signal peptide was found with a cleavage site between pos. 28 and 29 in the MsPOD protein. A phylogenetic comparison of the MsPOD protein and its orthologs in Medicago truncatula, Pisum sativum, Lupinus albus, Glycine max, Phaseolus vulgaris, Ficus carica, Linum usitatissimum, Populus trichocarpa, Hevea brasiliensis, Corylus avellana, $A$. thaliana, and $O$. sativa showed that MsPOD is most closely related to the ortholog from M. truncatula (Figure 1B).

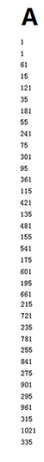

\section{$\mathbf{E}$}

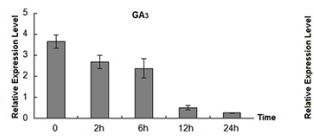

H

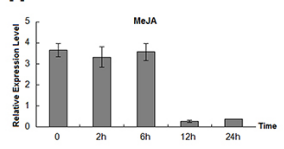

$\mathbf{F}$
B

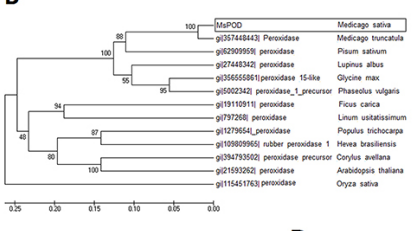

C
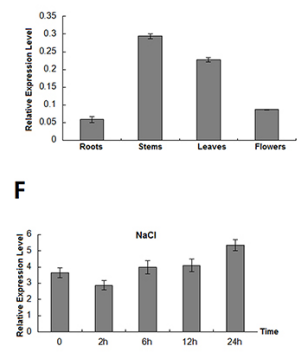

D

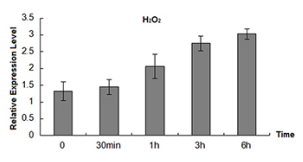

$\mathbf{G}$

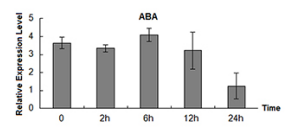

Figure 1. Analysis of $M S P O D$ and its expression patterns. A. $M S P O D$ encodes a polypeptide of 353 amino acids. B. Phylogenetic analysis of MsPOD protein orthologs. Sources of the orthologous proteins are indicated in parentheses. Bootstrap values are provided to indicate reliability at each node. C. Expression levels of $M S P O D$ in roots, stems, leaves, and flowers of wild-type (WT) alfalfa plants. D.-H. MsPOD expression levels after treatment with $2 \mathrm{mM} \mathrm{H}_{2} \mathrm{O}_{2}$ (D), $20 \mu \mathrm{M}$ gibberellic acid $\left(\mathrm{GA}_{3}\right)(\mathbf{E}), 200 \mathrm{mM} \mathrm{NaCl}(\mathbf{F}), 20 \mu \mathrm{M}$ abscisic acid (ABA) (G), and 3 $\mathrm{mM}$ methyl jasmonate (MeJA) $(\mathbf{H})$. Error bars represent SEs $(\mathrm{N}=3)$. 


\section{MsPOD expression patterns}

$M S P O D$ transcripts were detected in all of the alfalfa organs, including the roots, stems, leaves, and flowers. $M S P O D$ expression was higher in the stems and leaves than in the roots and flowers (Figure 1C). The expression level increased when $2 \mathrm{mM} \mathrm{H}_{2} \mathrm{O}_{2}$ was added (Figure 1D). MSPOD transcript levels under $\mathrm{H}_{2} \mathrm{O}_{2}$ conditions were time-dependent. Expression decreased after treatment with $20 \mu \mathrm{M} \mathrm{GA}_{3}^{2}$ (Figure 1E), but increased slightly when $200 \mathrm{mM} \mathrm{NaCl}$ was applied (Figure $1 \mathrm{~F}$ ). When the alfalfa was exposed to $20 \mu \mathrm{M} \mathrm{ABA}$ or $3 \mathrm{mM}$ MeJA, $M S P O D$ expression levels were not affected for the first $6 \mathrm{~h}$ but decreased drastically after $24 \mathrm{~h}$ (Figure $1 \mathrm{G}, \mathrm{H}$ ). The results show that $M s P O D$ was drastically induced under $\mathrm{H}_{2} \mathrm{O}_{2}$ conditions, indicating that it is involved in oxidative stress.

\section{Subcellular localization of MsPOD}

The PSORT program indicated that the MsPOD protein may appear outside of plant cells. To determine the subcellular localization of the MsPOD protein, the construct MsPODGFP driven by a $35 \mathrm{~S}$ promoter was applied to transform onion epidermal cells. The fusion protein MsPOD-GFP was localized to the extracellular space of onion epidermal cells (Figure 2), indicating that MsPOD is localized outside plant cells.

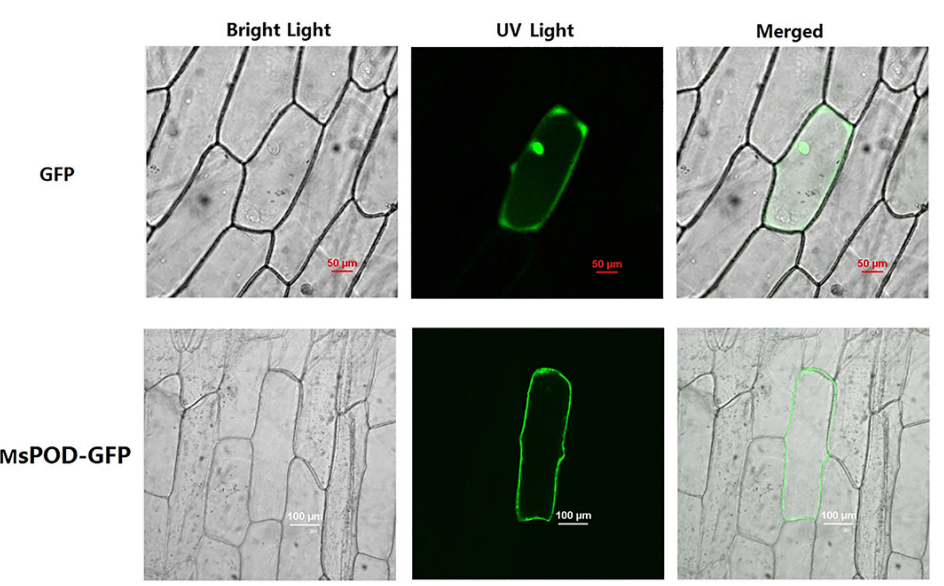

Figure 2. Subcellular localization of MsPOD in onion epidermal cells. Fluorescence due to an untargeted $35 \mathrm{~S}_{\text {pro }}:$ GFP plasmid was found in the whole onion cell. Red magnification bar, $50 \mu \mathrm{m}$. Fluorescence due to an MsPOD-GFP fusion protein was strongly detected in the extracellular space of onion epidermal cells. White magnification bar, $100 \mu \mathrm{m}$.

\section{Selection of transgenic Arabidopsis}

The full-length $M S P O D$ sequence was placed under the control of a CaMV-35S promoter. The resulting $35 \mathrm{~S}_{\mathrm{pro}}:: M S P O D$ construct was successfully transformed into $A$. thaliana, and 11 putative transgenic $35 \mathrm{~S}_{\mathrm{pro}}:: M S P O D$ Arabidopsis plants obtained after selection were confirmed as transgenic plants expressing $M S P O D$ by PCR, RT-PCR, and GUS staining (Figure 3A). The results show that four transgenic lines had high $M S P O D$ expression levels, which were selected to produce seeds and for further analysis. 


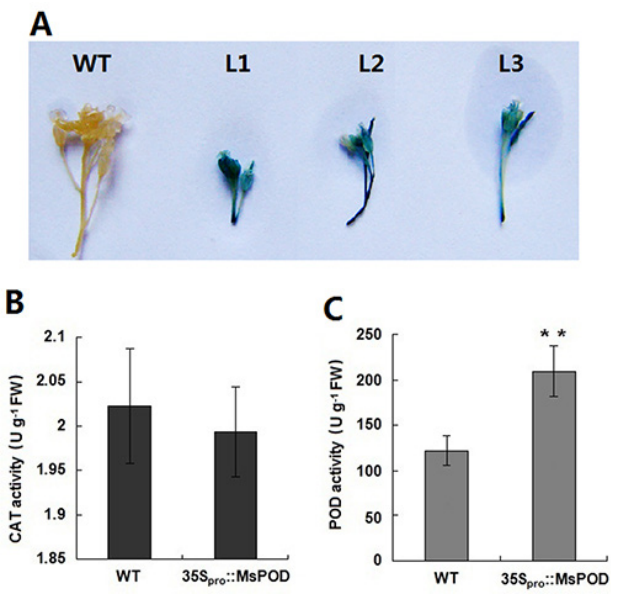

Figure 3. $\beta$-glucuronidase (GUS) expression and catalase (CAT) and peroxidase (POD) activity in transgenic and wild-type (WT) Arabidopsis plants. A. Representative GUS expression in $35 \mathrm{~S}_{\mathrm{pro}}:$ :GUS transgenic and WT plants. B. CAT activity in transgenic and WT plants. C. POD activity in transgenic and WT plants. Error bars represent SEs $(\mathrm{N}=4)$

\section{CAT and POD activity in transgenic plants}

There was no distinguishable difference in CAT activity between transgenic Arabidopsis and WT plants (Figure 3B), but POD activity had increased in the transgenic Arabidopsis plants (Figure 3C). These results show that MsPOD expression in transgenic Arabidopsis plants only increased POD activity, indicating that MSPOD increases POD activity in transgenic Arabidopsis plants.

\section{Expression of $\mathrm{MSPOD}$ enhances $\mathrm{NaCl}$ and $\mathrm{H}_{2} \mathrm{O}_{2}$ tolerance}

Based on its expression patterns under $\mathrm{H}_{2} \mathrm{O}_{2}$ conditions, we supposed that $M s P O D$ plays an important role in tolerance to abiotic stress. To assess $\mathrm{H}_{2} \mathrm{O}_{2}$ resistance in transgenic Arabidopsis plants, detached leaves were soaked in $3 \mathrm{mM} 2-(\mathrm{N}$-morpholino) ethanesulfonic acid (MES) with the addition of 2.5 or $5 \%(\mathrm{v} / \mathrm{v}) \mathrm{H}_{2} \mathrm{O}_{2}$ for three days. Leaf senescence was significantly delayed in $35 \mathrm{~S}_{\text {pro }}:: M s P O D$ transgenic plants, particularly with $5 \% \mathrm{H}_{2} \mathrm{O}_{2}$ (Figure $4 \mathrm{~A})$. The WT leaves faded to yellow, but leaves from the $35 \mathrm{~S}_{\mathrm{pro}}:: M S P O D$ transgenic plants were still partially green (Figure 4A). A similar pattern was observed of leaf chlorophyll content (Figure 4B). The chlorophyll content of the transgenic plants was much higher than that of the WT plants after treatment with $\mathrm{H}_{2} \mathrm{O}_{2}$ for three days, demonstrating that $M s P O D$ can increase tolerance to $\mathrm{H}_{2} \mathrm{O}_{2}$.

Seeds of transgenic Arabidopsis and WT plants were sown in $1 / 2$ MS plates with $0,50,100$, or $150 \mathrm{mM} \mathrm{NaCl}$ to assess their salt resistance. After growing on plates for 15 days, the transgenic seedlings exhibited enhanced salt tolerance. With $50 \mathrm{mM} \mathrm{NaCl}$, there was no obvious difference between WT and transgenic seedlings. The transgenic seedlings had longer roots than the WT seedlings after 100 or $150 \mathrm{mM} \mathrm{NaCl}$ was added to the $1 / 2$ MS plates (Figure 4C), indicating that MSPOD expression in transgenic Arabidopsis plants enhanced resistance to $\mathrm{NaCl}$. 


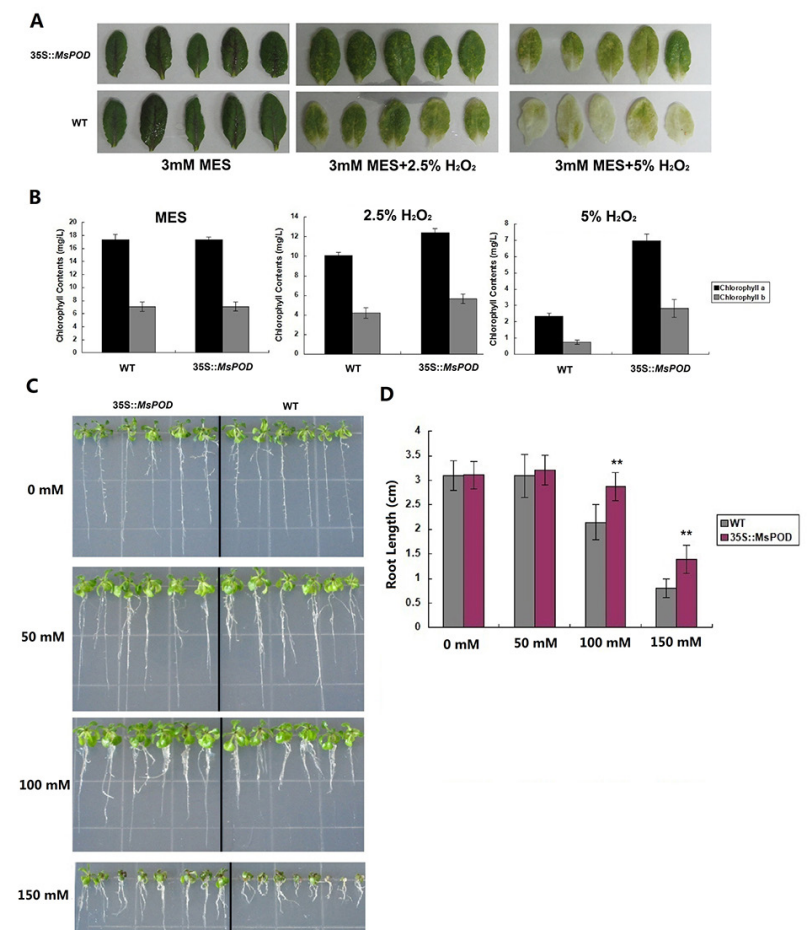

Figure 4. $\mathrm{H}_{2} \mathrm{O}_{2}$ and $\mathrm{NaCl}$ incubation of Arabidopsis $M s P O D$ transgenic plants. A. Detached third and fourth rosette leaves of wild-type (WT) and MsPOD transgenic plants were soaked in $3 \mathrm{mM} \mathrm{MES}$ with 2.5 or $5 \%(\mathrm{v} / \mathrm{v}) \mathrm{H}_{2} \mathrm{O}_{2}$. The leaves were photographed on the third day. B. Measurement of the chlorophyll content of the detached leaves. $\mathbf{C}$. Seedlings of transgenic and WT Arabidopsis plants were sown and grown on 1/2 Murashige and Skoog plates with $0,50,100$, or $150 \mathrm{mM} \mathrm{NaCl}$. D. Comparison of seedling root lengths in transgenic and WT Arabidopsis plants. Error bars represent SEs $(\mathrm{N}=3)$.

\section{DISCUSSION}

PODs play multiple biological roles in plants, including lignin biosynthesis, suberization, indole-3-acetic acid catabolism, $\mathrm{H}_{2} \mathrm{O}_{2}$ - and organic hydroperoxide-scavenging, growth regulation, and tolerance to biotic and abiotic stressors (Sanchez et al., 1983; Hiraga et al., 2001; Kim et al., 2004; Valério et al., 2004; Liu et al., 2005; Bae et al., 2011). It is very important to isolate and identify a novel POD gene from plants. In this study, we isolated and characterized a POD gene from alfalfa by the RT-PCR method. The coding domain sequence was $1062 \mathrm{bp}$ in length, which encoded 353 amino acids. The phylogenetic analysis showed that MsPOD is more structurally related to the POD from M. truncatula and is less related to other homologs.

Expression analysis showed that $M S P O D$ was most highly expressed in the stems and leaves (Figure 1C). This finding is in agreement with those from previous studies, demonstrating that the expression of many POD genes is tissue-specific (Wang et al., 2013; Yao et al., 2013). The relatively high $M S P O D$ expression level in the stems and leaves suggests that $M S P O D$ may be involved in defense responses in those organs. Previous studies have reported that POD genes play important roles in stress responses, and our expression analysis revealed that $M S P O D$ transcription increases with $\mathrm{H}_{2} \mathrm{O}_{2}$ or $\mathrm{NaCl}$ addition (Figure 1D, F), suggesting that 
$M S P O D$ might play an important role in preventing damage caused by $\mathrm{H}_{2} \mathrm{O}_{2}$ and $\mathrm{NaCl}$ during growth, which is in agreement with results from previous studies (Choi and Hwang 2012; Yao et al., 2013). CaPO2, which is a POD gene from pepper, is strongly induced by drought and $\mathrm{NaCl}$, with high expression levels being detected up to $25 \mathrm{~h}$ following treatment (Choi and Hwang 2012). The plant hormone ABA plays an important role in regulating and responding to abiotic stress by regulating genome-wide gene expression following drought, high salinity, and cold treatments. When alfalfa was exposed to $20 \mu \mathrm{M}$ ABA, MsPOD expression levels were not obviously affected after the first $6 \mathrm{~h}$, but expression decreased after $24 \mathrm{~h}$ (Figure 1G). This suggests that $M S P O D$ is not involved in the ABA signaling pathway. It seems probable that $M S P O D$ accumulation occurs in response to $\mathrm{H}_{2} \mathrm{O}_{2}$ and $\mathrm{NaCl}$ to prevent damage.

We analyzed the subcellular localization of the MsPOD protein using SignalP 4.1 Server, which showed that the MsPOD protein appeared outside of cells. Therefore, we expressed the MsPOD-GFP fusion protein in onion epidermal cells to confirm the subcellular localization. As predicted, the GFP signal appeared around the onion epidermal cells (Figure 2), which demonstrated that the MsPOD protein was localized outside cells. A previous study reported the subcellular localization of a POD protein, swpa4, in sweet potato, and showed that the sweet potato POD was secreted into the extracellular space (Kim et al., 2008). The extracellular space between cells seems to be where the MsPOD protein responds to abiotic stress.

$\mathrm{POD}$ and CAT play important roles in decreasing oxidative damage. In the enzymatic system, SOD constitutes the first line of defense against ROS by dismutating $\mathrm{O}_{2}^{-}$to $\mathrm{H}_{2} \mathrm{O}_{2}$. Subsequently, $\mathrm{H}_{2} \mathrm{O}_{2}$ is broken down by CAT, POD, and APX (Chen et al., 2015). We found that POD levels had significantly increased in $M S P O D$ transgenic Arabidopsis plants compared to those in WT plants, but CAT levels had not changed. Similarly, (Kim et al., 2008) reported that POD activity in swpa 4 transgenic plants was approximately 50-fold higher than that in control plants. POD activity in $C A n P O D$-silenced plants was drastically reduced compared to that in control plants (Wang et al., 2013). These results indicate that the overexpression of $M S P O D$ increases $\mathrm{H}_{2} \mathrm{O}_{2}$ tolerance in transgenic plants.

ROS are one of the most destructive substances to plants, and are generated under severe abiotic and biotic environmental conditions. PODs are thought to protect plants against oxidative stress. To date, many POD genes have been cloned and identified in various plant species, and many of them play important roles in abiotic or biotic resistance. For example, POD genes in wheat are involved in powdery mildew infection (Liu et al., 2005). Overexpression of a potato POD gene (swpa4) significantly increases salt- and drought-stress tolerance in transgenic plants (Kim et al., 2008). Overexpression of the pepper CaPO2 gene in transgenic Arabidopsis plants not only increases tolerance to salt, drought, and oxidative stress, but also increases resistance to infection by the necrotrophic fungal pathogen, Alternaria brassicicola (Choi and Hwang 2012). Recently, (Wang et al., 2013) found that a novel CanPOD gene in pepper is involved in defense responses to Phytophthora capsici infection and abiotic stress tolerance. Based on the expression patterns of alfalfa $M S P O D$ in response to $\mathrm{H}_{2} \mathrm{O}_{2}$ or $\mathrm{NaCl}$ addition, we suggest that $M s P O D$ could decrease damage caused by abiotic stress. In addition, the expression of a tomato POD gene, $T P X 2$, in transgenic tobacco increases germination rate under high-salinity conditions (Amaya et al., 1999). We found that tolerance to $\mathrm{NaCl}$ and $\mathrm{H}_{2} \mathrm{O}_{2}$ increased when $M S P O D$ was expressed in transgenic Arabidopsis plants. After treatment with $\mathrm{H}_{2} \mathrm{O}_{2}$ for three days, $M s P O D$ transgenic plants exhibited increased resistance to $\mathrm{H}_{2} \mathrm{O}_{2}$ and leaf senescence was delayed (Figure 4A). Chlorophyll content is also an important factor in the stress responses of plants; plants with high abiotic tolerance have 
a high chlorophyll content (Sanchez et al., 1983; Bijanzadeh and Emam 2010). We found no significant difference in chlorophyll content between transgenic and WT leaves without $\mathrm{H}_{2} \mathrm{O}_{2}$, but it significantly decreased when treated with $\mathrm{H}_{2} \mathrm{O}_{2}$. The chlorophyll content of transgenic leaves was significantly higher than that of WT leaves, suggesting that MsPOD increased the $\mathrm{H}_{2} \mathrm{O}_{2}$ tolerance of the transgenic plants. Many genes that are involved in $\mathrm{NaCl}$ tolerance have been identified, and breeders have investigated the genetic mechanisms involved (Saeed et al., 2011). We also found that $M S P O D$ is involved in $\mathrm{NaCl}$ resistance. Heterologous $M S P O D$ expression improved the $\mathrm{NaCl}$ tolerance of transgenic plants treated with 100 or $150 \mathrm{mM}$ $\mathrm{NaCl}$ compared to that of control plants. These results demonstrate that MSPOD increases resistance to $\mathrm{H}_{2} \mathrm{O}_{2}$ and $\mathrm{NaCl}$.

We found that $M S P O D$ expression increased abiotic stress tolerance. It appears that the involvement of MsPOD may be induced by abiotic stressors such as $\mathrm{NaCl}$ and $\mathrm{H}_{2} \mathrm{O}_{2}$, not via $\mathrm{ABA}$ or because of $\mathrm{POD}$ regulation. In conclusion, we isolated a POD gene named $M s P O D$ from alfalfa, the expression of which was induced by $\mathrm{NaCl}$ and $\mathrm{H}_{2} \mathrm{O}_{2}$. The putative protein was localized outside of the cells. $M S P O D$ expression in transgenic plants increased tolerance to $\mathrm{NaCl}$ and $\mathrm{H}_{2} \mathrm{O}_{2}$.

\section{Conflicts of interests}

The authors declare no conflict of interest.

\section{ACKNOWLEDGMENTS}

Research supported by the Fundamental Research Funds for the Central Universities (\#BLX2014-06).

\section{REFERENCES}

Amaya I, Botella MA, de la Calle M, Medina MI, et al. (1999). Improved germination under osmotic stress of tobacco plants overexpressing a cell wall peroxidase. FEBS Lett. 457: 80-84.http://dx.doi.org/10.1016/S0014-5793(99)01011-X

Bae H, Roberts DP, Lim HS, Strem MD, et al. (2011). Endophytic Trichoderma isolates from tropical environments delay disease onset and induce resistance against Phytophthora capsici in hot pepper using multiple mechanisms. Mol. Plant Microbe Interact. 24: 336-351. http://dx.doi.org/10.1094/MPMI-09-10-0221

Bijanzadeh E and Emam Y (2010). Effect of defoliation and drought stress on yield components and chlorophyll content of wheat. Pak. J. Biol. Sci. 13: 699-705.http://dx.doi.org/10.3923/pjbs.2010.699.705

Cervera M (2005). Histochemical and fluorometric assays for uidA (GUS) gene detection. Methods Mol. Biol. 286: 203-214.

Chao Y, Kang J, Sun Y, Yang Q, et al. (2009). Molecular cloning and characterization of a novel gene encoding zinc finger protein from Medicago sativa L. Mol. Biol. Rep. 36: 2315-2321.http://dx.doi.org/10.1007/s11033-009-9450-5

Chen Y, Cai J, Yang FX, Zhou B, et al. (2015). Ascorbate peroxidase from Jatropha curcas enhances salt tolerance in transgenic Arabidopsis. Genet. Mol. Res. 14: 4879-4889. http://dx.doi.org/10.4238/2015.May.11.20

Choi HW and Hwang BK (2012). The pepper extracellular peroxidase $\mathrm{CaPO} 2$ is required for salt, drought and oxidative stress tolerance as well as resistance to fungal pathogens. Planta 235: 1369-1382.http://dx.doi.org/10.1007/s00425$\underline{011-1580-\mathrm{z}}$

Clough SJ and Bent AF (1998). Floral dip: a simplified method for Agrobacterium-mediated transformation of Arabidopsis thaliana. Plant J. 16: 735-743. http://dx.doi.org/10.1046/j.1365-313x.1998.00343.x

Demiral T and Turkan I (2005). Comparative lipid peroxidation, antioxidant defense systems and proline content in roots of two rice cultivars differing in salt tolerance. Environ. Exp. Bot. 53: 247-257. http://dx.doi.org/10.1016/j. envexpbot.2004.03.017

Gonçalves LSA, Rodrigues R, Diz MSS, Robaina RR, et al. (2013). Peroxidase is involved in Pepper yellow mosaic virus resistance in Capsicum baccatum var. pendulum. Genet. Mol. Res. 12: 1411-1420. http://dx.doi.org/10.4238/2013. April.26.3 
Hiraga S, Sasaki K, Ito H, Ohashi Y, et al. (2001). A large family of class III plant peroxidases. Plant Cell Physiol. 42: 462-468. http://dx.doi.org/10.1093/pcp/pce061

Kim SS, Choi SY, Park JH and Lee DJ (2004). Regulation of the activity of Korean radish cationic peroxidase promoter during dedifferentiation and differentiation. Plant Physiol. Biochem. 42: 763-772. http://dx.doi.org/10.1016/j. plaphy.2004.09.004

Kim YH, Kim CY, Song WK, Park DS, et al. (2008). Overexpression of sweetpotato swpa4 peroxidase results in increased hydrogen peroxide production and enhances stress tolerance in tobacco. Planta 227: 867-881. http://dx.doi. org/10.1007/s00425-007-0663-3

Li FF, Zhan D, Xu LX, Han LB, et al. (2014). Antioxidant and hormone responses to heat stress in two Kentucky bluegrass cultivars contrasting in heat tolerance. J. Am. Soc. Hortic. Sci. 139: 587-596.

Liang Y, Chen Q, Liu Q, Zhang W, et al. (2003). Exogenous silicon (Si) increases antioxidant enzyme activity and reduces lipid peroxidation in roots of salt-stressed barley (Hordeum vulgare L.). J. Plant Physiol. 160: 1157-1164. http:// dx.doi.org/10.1078/0176-1617-01065

Liu G, Sheng X, Greenshields DL, Ogieglo A, et al. (2005). Profiling of wheat class III peroxidase genes derived from powdery mildew-attacked epidermis reveals distinct sequence-associated expression patterns. Mol. Plant Microbe Interact. 18: 730-741. http://dx.doi.org/10.1094/MPMI-18-0730

Maehly AC and Chance B (1954). The assay of catalases and peroxidases. Methods Biochem. Anal. 1: 357-424. http:// dx.doi.org/10.1002/9780470110171.ch14

Mittova V, Guy M, Tal M and Volokita M (2004). Salinity up-regulates the antioxidative system in root mitochondria and peroxisomes of the wild salt-tolerant tomato species Lycopersicon pennellii. J. Exp. Bot. 55: 1105-1113. http:// dx.doi.org/10.1093/jxb/erh113

Passardi F, Cosio C, Penel C and Dunand C (2005). Peroxidases have more functions than a Swiss army knife. Plant Cell Rep. 24: 255-265.http://dx.doi.org/10.1007/s00299-005-0972-6

Petersen TN, Brunak S, von Heijne G and Nielsen H(2011). SignalP 4.0: discriminating signal peptides from transmembrane regions. Nat. Methods 8: 785-786. http://dx.doi.org/10.1038/nmeth.1701

Saeed A, Shahid MQ, Anjum SA, Khan AA, et al. (2011). Genetic analysis of $\mathrm{NaCl}$ tolerance in tomato. Genet. Mol. Res. 10: 1754-1776. http://dx.doi.org/10.4238/vol10-3gmr1198

Sanchez RA, Hall AJ, Trapani N and de Hunau RC (1983). Effects of water stress on the chlorophyll content, nitrogen level and photosynthesis of leaves of two maize genotypes. Photosynth. Res. 4: 35-47. http://dx.doi.org/10.1007/ $\underline{\mathrm{BF} 00041799}$

Tamura K, Peterson D, Peterson N, Stecher G, et al. (2011). MEGA5: molecular evolutionary genetics analysis using maximum likelihood, evolutionary distance, and maximum parsimony methods. Mol. Biol. Evol. 28: 2731-2739. http://dx.doi.org/10.1093/molbev/msr121

Valério L, De Meyer M, Penel C and Dunand C (2004). Expression analysis of the Arabidopsis peroxidase multigenic family. Phytochemistry 65: 1331-1342.http://dx.doi.org/10.1016/j.phytochem.2004.04.017

Wang JE, Liu KK, Li DW, Zhang YL, et al. (2013). A novel peroxidase CanPOD gene of pepper is involved in defense responses to Phytophthora capsici infection as well as abiotic stress tolerance. Int. J. Mol. Sci. 14: 3158-3177. http:// dx.doi.org/10.3390/ijms14023158

Yao P, Lu W, Meng F, Wang X, et al. (2013). Molecular cloning, expression and oxidative stress response of a mitochondrial thioredoxin peroxidase gene (AccTpx-3) from Apis cerana cerana. J. Insect Physiol. 59: 273-282. http://dx.doi.org/10.1016/j.jinsphys.2012.11.005

Yun BW, Huh GH, Lee HS, Kwon SY, et al. (2000). Differential resistance to methyl viologen in transgenic tobacco plants that express sweet potato peroxidases. J. Plant Physiol. 156: 504-509. http://dx.doi.org/10.1016/S0176$\underline{1617(00) 80165-0}$ 